\title{
Pengaruh Konsentrasi Inhibitor Ekstrak Daun Teh (Camelia sinensis) Terhadap Laju Korosi Baja API 5L
}

\author{
Maulana Fazdri ${ }^{1}$, Iman Saefuloh ${ }^{2}$, Nufus Kanani ${ }^{3}$ \\ ${ }^{1,2}$ Teknik Mesin, Universitas Sultan Ageng Tirtayasa, Indonesia \\ ${ }^{3}$ Teknik Kimia, Universitas Sultan Ageng Tirtayasa, Indonesia \\ 1mfazdri@gmail.com
}

\begin{abstract}
ABSTRAK
Penggunaan baja pada saat ini telah berkembang pesat dan digunakan dalam teknologi industri sebagai salah satu material penunjang. Ada beberapa penggunaan baja yang digunakan pada industri sepeda motor, kereta api, mobil, kapal laut, serta kontruksi lainnya. Namun dalam penggunaan baja, banyak faktor yang menyebabkan daya guna baja ini menurun. Salah satu penyebabnya yaitu fenomena korosi pada baja. Penelitian ini bertujuan untuk mengetahui pengaruh konsentrasi inhibitor ekstrak daun teh terhadap laju korosi pada baja API 5L dan menghambat laju korosi pada baja API 5L. Penelitian ini menggunakan metode kehilangan berat. Media korosif yang dipakai adalah $\mathrm{NaCl}$ dan $\mathrm{HCl}$. Perendaman dilakukan selama 10 hari guna mengukur kemampuan inhibitor menghambat laju korosi. Metode pembuatan inihibitor ekstrak daun teh menggunakan ultrasonic bath. Konsentrasi inhibitor yang dibuat pada penelitian ini adalah $1 \%, 3 \%, 5 \%, 7 \%$, dan 9\%. Sebelum baja direndam dalam larutan korosif, larutan korosif dicampur terlebih dahulu dengan larutan inhibitor sesuai dengan konsentrasinya. Hasil penelitian menunjukkan bahwa efisiensi inhibisi korosi yang paling besar terjadi pada larutan korosif $\mathrm{NaCl}$ dengan konsentrasi $9 \%$ pada perendaman selama 10 hari yaitu sebesar $95 \%$ dan pada larutan korosif $\mathrm{HCl}$ dengan konsentrasi $9 \%$ sebesar $45 \%$. Morfologi permukaan yang diperoleh menggunakan Scanning Electron Microscope dari baja API 5L menampilkan permukaan baja yang telah ditambahkan dengan ekstrak daun teh mengalami korosi lebih sedikit. Hal ini menunjukkan bahwa inhibitor ekstrak daun teh baik dalam menghambat laju korosi yang terjadi pada baja API 5L.
\end{abstract}

Kata kunci: baja API 5L, korosi, laju korosi, ekstrak daun teh, inhibitor efisiensi inhibisi.

\begin{abstract}
Effect Of Inhibitor Concentration Of Tea Leaf (Camelia sinensis) Extract On Corrosion Of 5L API

Steel. The use of steel at this time has grown rapidly and is used in industrial technology as one of the supporting materials. There are several uses of steel used in the motorcycle, railway, car, marine, and other construction industries. But in the use of steel, many factors cause the power of this steel to decrease. One of the causes is the phenomenon of corrosion in steel. This research aims to determine the effect of tea leaf extract inhibitor concentrations on corrosion rates on API $5 L$ steel and inhibit corrosion rates in API 5L steel. The method used is mass reduction. The corrosive medium used is $\mathrm{NaCl}$ and $\mathrm{HCl}$. The length of immersion is 10 days to see the inhibitor's ability to inhibit corrosion rate. The method of making inihibitor extracts tea leaves using an ultrasonic bath. The concentration of inhibitors made in this study was 1\%, $3 \%, 5 \%, 7 \%$, and 9\%. Before the steel is soaked in a corrosive solution, the corrosive solution is mixed first with the inhibitor solution according to its concentration. The results showed that the largest efficiency of corrosion inhibition occurred in the corrosive solution of $\mathrm{NaCl}$ with a concentration of 9\% in immersion for 10 days which is $95 \%$ and in the corrosive solution of $\mathrm{HCl}$ with a concentration of $9 \%$ of $45 \%$. Surface morphology obtained using api $5 \mathrm{~L}$ electron microscope scanning shows the steel surface coated with tea leaf extract is corrosiond less. This suggests that tea leaf extract inhibitors are good at inhibiting the rate of corrosion that occurs in API 5L steel.
\end{abstract}

Keywords: API 5L Steel, Corrosion, Corrosion Rate, Tea Leaf Extract, Inhibitor, Inhibition Efficiency. 


\section{Dinamika : Jurnal Ilmiah Teknik Mesin}

\section{PENDAHULUAN}

Adanya korosi pada industri perminyakan memberikan dampak yang signifikan terhadap beberapa perspektif yaitu tumpahan minyak yang menyebabkan pencemaran lingkungan, penghentian proses produksi oleh proses penggantian, dan peningkatan biaya operasional. Kejadian ini dialami oleh PT. Terminal BBM Pertamina Trading Unit 1 (Persero) di Teluk Kabung, Jl Raya Padang-Painan KM 24 Padang, yang mengalami dua kali kebocoran pipa dalam 3 tahun terakhir. Kebocoran yang terjadi di kawasan pelabuhan disebabkan karena pipa biasanya tersiram gelombang laut [2]. Korosi adalah penurunan kualitas yang disebabkan oleh reaksi kimia suatu bahan logam dengan unsur lain di alam [1]. Fenomena korosi tidak dapat sepenuhnya dicegah, tetapi kecepatannya dapat dikurangi. Berbagai cara telah dilakukan untuk mengurangi laju korosi, termasuk penggunaan inhibitor. Sampai saat ini, penggunaan inhibitor telah menjadi salah satu cara paling efektif untuk mengurangi laju korosi karena biayanya yang relatif rendah dan pengoperasian yang sederhana [3]. Inhibitor digunakan untuk melindungi bagian dalam struktur dari kerusakan korosi akibat aliran atau penyimpanan fluida di dalamnya. Inhibitor umumnya menambahkan sedikit di lingkungan asam, air pendingin, uap atau lingkungan lain. Manfaat menggunakan inhibitor meliputi; memperpanjang umur struktur atau material, mencegah gangguan proses produksi, mencegah kecelakaan korosi, menghindari kontaminasi produk dan sebagainya [4].

Akan tetapi, banyak juga inhibitor anorganik yang dapat mengurangi laju korosi namun, inhibitor anorganik ini bersifat tidak ramah lingkungan. Maka dari itu, hal inilah yang mendorong kami untuk melakukan penelitian ini dengan menggunakan inhibitor organik yaitu dengan bahan dasar daun teh. Dalam sebuah penelitian jenis tumbuhan yang mengandung tanin pada bagian daunnya adalah teh (Camelia sinensis) dengan kandungan tanin sebesar $17,68 \%$ [5].

Penelitian lain yang dilakukan terhadap pengaruh konsentrasi inhibitor ekstrak daun teh (Camelia sinensis) menunjukkan efisiensi penghambatan korosi tertinggi terjadi pada konsentrasi $4 \%$, baik selama perendaman 3 hari maupun 6 hari. dengan efisiensinya masing-masing $74,32 \%$ dan $73,41 \%$ [2]. Penelitian sebelumnya mengenai pengendalian laju korosi baja dengan media natrium klorida menggunakan inhibitor dari ekstrak daun teh (Camellia sinensis) menunjukkan bahwa nilai efisiensi inhibisi tertinggi diperoleh dengan penambahan konsentrasi inhibitor $10 \%$ selama perendaman 4 hari mendapatkan nilai efisiensi sebesar $92 \%$. Hal ini menunjukkan bahwa inhibitor ekstrak daun teh sangat efektif dalam mengendalikan laju korosi media natrium klorida. [6]. Kelebihan menggunakan inhibitor organik yaitu sifat inhibitor yang ramah lingkungan dan mudah untuk didapatkan dengan melalui proses yang sederhana.

Penelitian ini bertujuan untuk mengetahui pengaruh konsentrasi inhibitor ekstrak daun teh terhadap laju korosi pada baja API 5L dan menghambat laju korosi pada baja API 5L.

\section{METODE}

Metode yang digunakan untuk mengetahui nilai laju korosi pada penelitian ini adalah weight loss atau metode kehilangan berat. Dimana sampel baja yang telah direndam pada medium korosif dengan penambahan variasi konsentrasi inhibitor sebesar $1 \%$, $3 \%, 5 \%, 7 \%$, dan $9 \%$ mencapai waktu korosi yang di inginkan yaitu selama 10 hari.

\section{Preparasi sampel baja}

Baja API 5L dibuat menjadi specimen uji berbentuk plat dengan dimensi $2 \times 2 \mathrm{~cm}$ dan dengan ketebalan $0,3 \mathrm{~cm}$ sejumlah 12 specimen. Kemudian permukaan spesimen uji dilakukan proses grinding menggunakan amplas 120 grid dan dimasukkan kedalam larutan aseton guna membersihkan partikel yang terdapat pada permukaan spesimen. Lalu spesimen ditimbang guna menentukan massa awal.

\section{Pembuatan inhibitor ekstrak daun teh}

Pembuatan inhibitor dari ekstrak daun teh dilakukan dengan cara memblender daun teh yang sudah dikering anginkan sampai halus, lalu mengayak bubuk daun teh yang sudah di blender dengan menggunakan saringan 80 mesh. Setelah itu bubuk daun teh yang telah disaring di 
timbang sebanyak 10 gram dengan menggunakan timbangan digital, kemudian dimasukkan ke dalam gelas beaker $500 \mathrm{ml}$, lalu membuat larutan dengan campuran etanol - aquades dengan perbandingan 1:4 pada labu ukur $200 \mathrm{ml}$. Hasil dari pencampuran ini kemudian di masukan ke dalam gelas beaker yang berisi 10 gram bubuk daun teh lalu diaduk hingga merata. Setelah itu di masukan ke dalam ultrasonic bath guna mengekstrak daun teh selama 60 menit. Hasil dari ekstraksi tersebut kemudian di filtrasi menggunakan kertas saring guna memisahkan fitrat dan residu. Kemudian fitrat hasil penyaringan di evaporasi (penguapan) menggunakan alat penguap putar vakum (rotary evaporator) guna memisahkan pelarut atau solvent dari larutan, sehingga mendapatkan larutan yang pekat dengan konsentrasi yang lebih tinggi.

\section{Pembuatan larutan korosif $\mathrm{NaCl}$ dan $\mathrm{HCl}$}

Pelarutan $\mathrm{NaCl}$ dilakukan dengan menimbang 5,9 gram $\mathrm{NaCl}$ menggunakan timbangan digital kemudian melarutkannya dengan menambahkan 5,9 gram $\mathrm{NaCl}$ ke dalam labu ukur $100 \mathrm{ml}$ dan menambahkan aquades hingga batasnya. Untuk larutan $\mathrm{HCl}$ dibuat dengan cara mengencerkan 0,82 $\mathrm{ml}$ larutan $\mathrm{HCl}$ dengan penambahan aquades ke dalam labu ukur $100 \mathrm{ml}$ di ujung labu kemudian diaduk untuk proses pengenceran $\mathrm{HCl}$.

\section{Perendaman sampel}

Adapun proses perendaman sampel baja pada penelitian ini ditunjukkan pada gambar 1 .

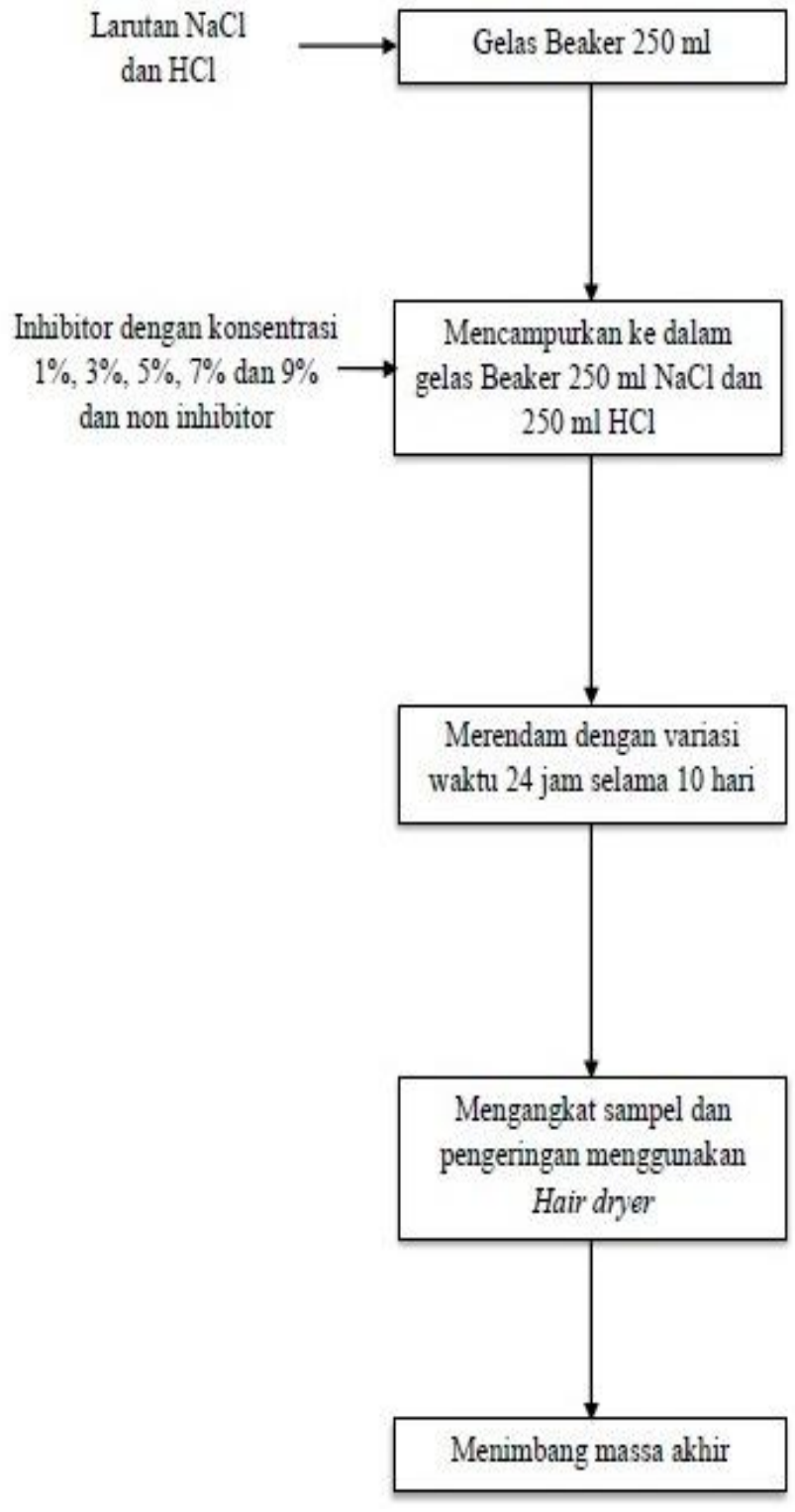

Gambar 1. Diagram alir perendaman

\section{HASIL DAN PEMBAHASAN}

3.1 Laju korosi sebelum dan sesudah penambahan inhibitor pada 10 hari perendaman.

Pada pengujian laju korosi dengan perendaman selama 10 hari dengan media korosif $\mathrm{NaCl}$ dan $\mathrm{HCl}$, terdapat perbedaan antara sampel baja yang mendapat inhibitor dan yang tidak mendapat inhibitor larutan ekstrak daun teh. Pada konsentrasi yang berbeda dari larutan inhibitor yang diberikan, terdapat indikasi penurunan laju korosi setelah penambahan larutan inhibitor, seperti yang ditunjukkan pada Gambar 2 dan 3. 


\section{Dinamika : Jurnal Ilmiah Teknik Mesin}

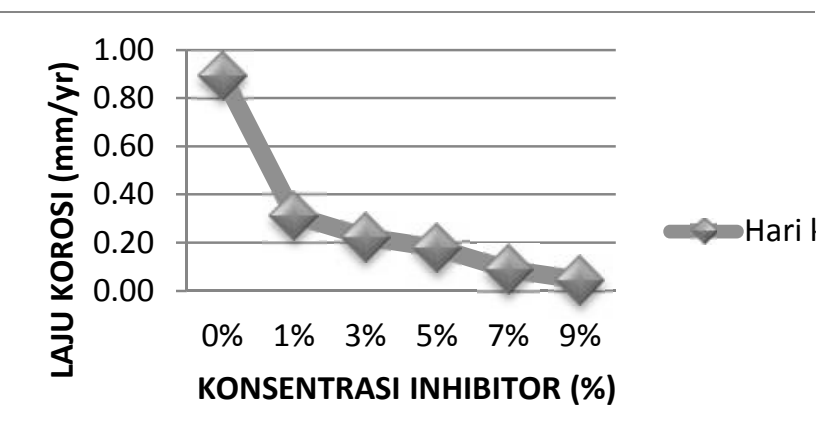

Gambar 2. Grafik konsentrasi ekstrak inhibitor terhadap laju korosi baja API 5L pada media korosif $\mathrm{NaCl}$.

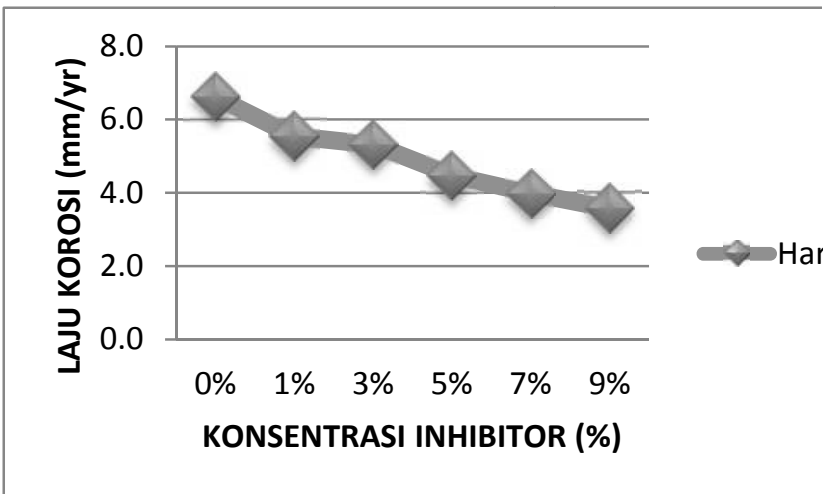

Gambar 3. Grafik konsentrasi ekstrak inhibitor terhadap laju korosi baja API 5L pada media korosif $\mathrm{HCl}$.

Gambar 2 dan Gambar 3 menunjukkan bahwa pada konsentrasi penambahan ekstrak daun teh $0 \%$ atau tanpa penambahan inhibitor nilai laju korosinya besar. Setelah diaplikasikan inhibitor dengan peningkatan konsentrasi tertentu, grafik menunjukkan penurunan laju korosi konsentrasi inhibitor dari $1 \%$ sampai $9 \%$. Ini karena inhibitor bertindak sebagai inhibitor korosi. Semakin tinggi nilai konsentrasi inhibitor maka semakin rendah nilai korosinya. Nilai laju korosi tertinggi pada spesimen uji yang sudah diberikan inhibitor sebesar $9 \%$ pada larutan $\mathrm{NaCl}$ adalah $0,004 \mathrm{~mm} / \mathrm{yr}$ (mpy) sedangkan pada penelitian sebelum nya yang telah dilakukan oleh Ludiana (2012) hanya mendapatkan 0,003 $\mathrm{g} / \mathrm{cm}^{2}$ hari. Artinya pada penelitian ini laju korosi yang terjadi pada spesimen uji sebesar 0,004 mils per year atau mili inchi per tahun nya. Penurunan nilai laju korosi terhadap baja API 5L dengan berbagai konsentrasi inhibitor yang diberikan menunjukkan bahwa ekstrak daun teh dapat digunakan sebagai inhibitor. Dalam hal ini inhibitor berperan sebagai inhibitor korosi karena tanin pada ekstrak daun teh mengikat besi membentuk perisai yang melindungi baja dari korosi.

3.2 Efisiensi inhibisi ekstrak daun teh setelah spesimen uji direndam selama 10 hari.

Dengan perendaman dalam medium korosif $\mathrm{NaCl}$ dan $\mathrm{HCl}$ selama 10 hari, pemberian inhibitor mempunyai efek menurunkan laju korosi dan penghambatan diukur dengan nilai efisiensi. Hasil percobaan dengan metode reduksi massa dapat dilihat pada Gambar 4 dan 5.

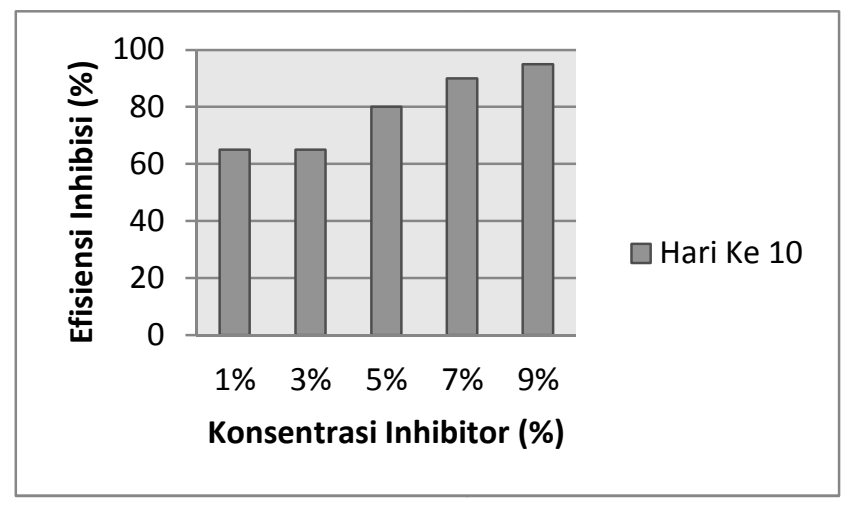

Gambar 4. Grafik konsentrasi inhibitor terhadap efisiensi inhibisi pada larutan korosif $\mathrm{NaCl}$.

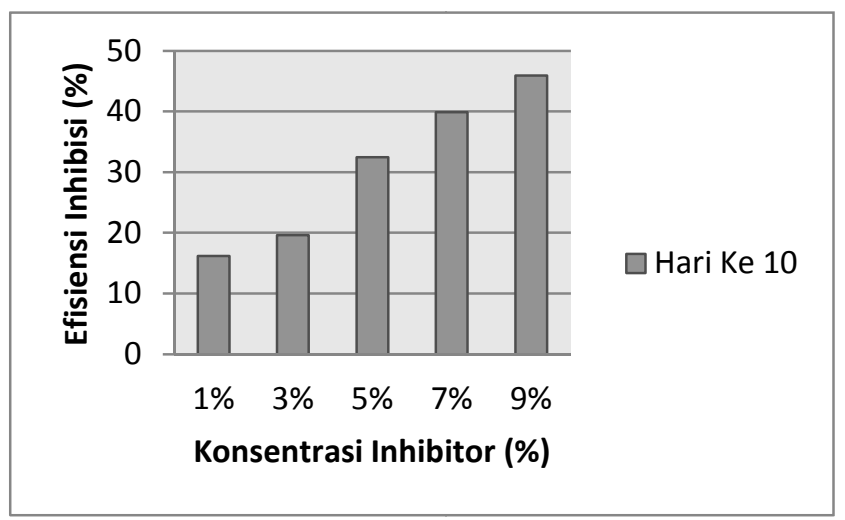

Gambar 5. Grafik konsentrasi inhibitor terhadap efisiensi inhibisi pada larutan korosif $\mathrm{HCl}$.

Dari Gambar 4 dan Gambar 5 dapat dilihat bahwa nilai efisiensi inhibisi ekstrak daun teh terhadap korosi baja API 5L cenderung meningkat dengan meningkatnya konsentrasi, semakin tinggi konsentrasi inhibitor maka semakin tinggi nilai yang diperoleh dari efisiensi penghambatan. Pada Gambar 4 dapat dilihat bahwa efisiensi inhibisi tertinggi terdapat pada media korosif $\mathrm{NaCl}$ yang mencapai 95\% pada konsentrasi inhibitor ekstrak daun teh $9 \%$ setelah direndam selama 240 jam (10 hari). Sedangkan pada Gambar 5 dapat dilihat 
bahwa efisiensi hambat tertinggi terdapat pada media korosif dengan $\mathrm{HCl}$ yaitu mencapai $46 \%$ dengan konsentrasi inhibitor ekstrak daun teh $9 \%$ dalam waktu 240 jam (10 hari). Hal ini menunjukkan bahwa inhibitor ekstrak daun teh lebih efisien dalam menurunkan laju korosi baja API 5L pada media korosif $\mathrm{NaCl}$. Pada media korosif dengan $\mathrm{HCl}$, inhibitor ekstrak daun teh tidak dapat menurunkan laju korosi baja API 5L seefisien pada media korosif dengan $\mathrm{NaCl}$, karena kandungan asam lebih tinggi dari pada kadar asam $\mathrm{NaCl}$ sendiri, sehingga inhibitor ekstrak daun teh tidak optimal untuk mengurangi laju korosi pada media korosif $\mathrm{HCl}$. Adapun pada penelitian sebelumnya yang telah dilakukan oleh Ludiana (2012) dan Desi Mitra Sari (2013) mendapatkan nilain efisiensi inhibisi sebesar $73,41 \%$ dan $92 \%$ pada media korosif $\mathrm{NaCl}$. Sedangkan pada penelitian ini efisiensi inhibisi pada media korosif $\mathrm{NaCl}$ mendapatkan nilai sebesar $95 \%$.

\subsection{Foto morfologi permukaan baja API 5L}

Foto struktur permukaan baja API 5L diperoleh dengan menggunakan scanning electron microscope.

3.3.1 Hasil Scanning Electron Microscope (SEM) dengan pembesaran 2000 kali tanpa menggunakan inhibitor dengan waktu perendaman 10 hari pada medium korosif $\mathrm{NaCl}$ dan $\mathrm{HCl}$.

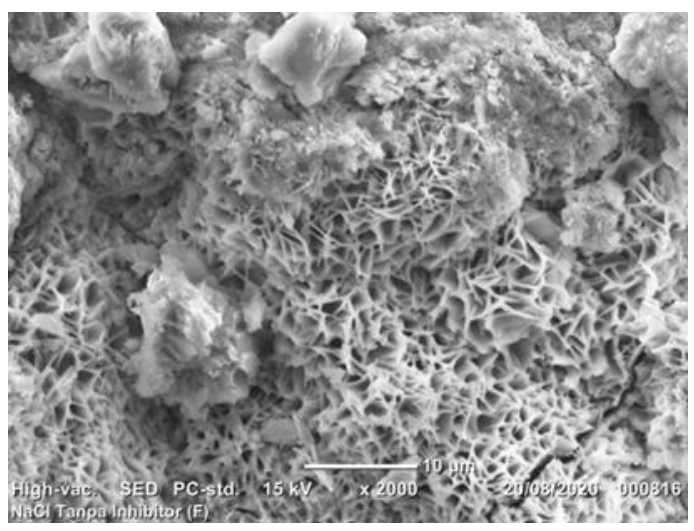

Gambar 6. Foto Hasil SEM dari Baja API 5L pembesaran 2000 kali yang direndam pada pelarut medium korosif $\mathrm{NaCl}$ selama 10 hari tanpa inhibitor.

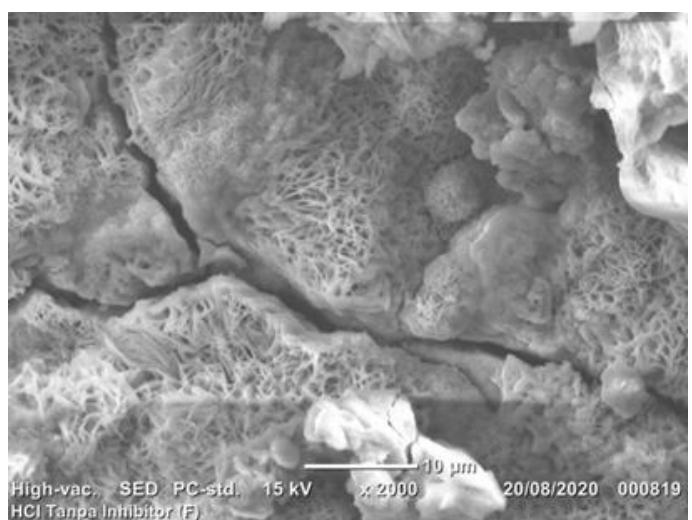

Gambar 7. Foto Hasil SEM dari Baja API 5L pembesaran 2000 kali yang direndam pada pelarut medium korosif $\mathrm{HCl}$ selama 10 hari tanpa inhibitor.

Hasil analisis SEM pada Gambar 6 dan 7 menunjukkan permukaan pada Baja API 5L terdapat gumpalan gumpalan (cluster) dengan ukuran yang bervariasi tersebar hampir pada semua permukaannya, adapun juga terlihat retakan - retakan (crack) pada permukaannya, dan terdapat juga lubang (hole) berbentuk Kristal pada permukaan. Korosi retak (crack) dan lubang (hole) yang terjadi pada lapisan permukaan spesimen uji inilah yang menyebabkan terjadinya korosi, karena keduanya adalah jalan masuk untuk oksigen. Seperti pada penelitian sebelumnya yang dilakukan oleh Priyotomo (2008) menjelaskan bahwa adanya terjadi korosi lokal yaitu korosi celah, korosi sumuran, dan korosi retak tegang disebabkan oleh kerapuhan pada lapisan oksida.

\subsubsection{Hasil Scanning Electron Microscope (SEM)} pembesaran 2000 kali dengan penambahan konsentrasi inhibitor sebesar 9\% dengan waktu perendaman 10 hari pada medium korosif $\mathrm{NaCl}$ dan $\mathrm{HCl}$.

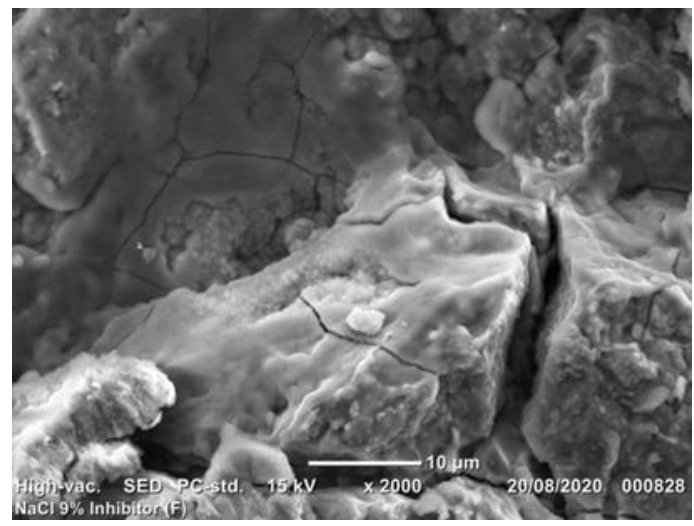

Gambar 8. Foto Hasil SEM dari Baja API 5L pembesaran 2000 kali yang direndam pada pelarut medium korosif $\mathrm{NaCl}$ selama 10 hari dengan penambahan inhibitor. 


\section{Dinamika : Jurnal Ilmiah Teknik Mesin}

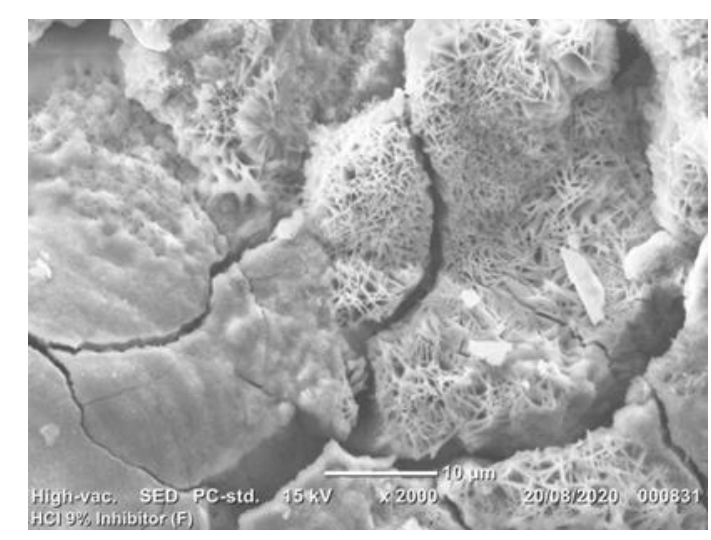

Gambar 9. Foto Hasil SEM dari Baja API 5L pembesaran 2000 kali yang direndam pada pelarut medium korosif $\mathrm{HCl}$ selama 10 hari dengan penambahan inhibitor.

Hasil analisis SEM pada Gambar 8 dan 9 menunjukkan permukaan dari Baja API 5L yang telah dilapisi dengan inhibitor ekstrak daun teh dengan konsentrasi 9\% dan medium korosif yang berbeda. Hasil yang ditunjukkan pada Gambar 8 menunjukkan dengan konsentrasi inhibitor ekstrak daun teh sebesar 9\% dalam larutan korosif $\mathrm{NaCl}$ dengan perbesaran 2000 kali terlihat berkurangnya lubang (hole) yang berbentuk kristal, tersisa hanya sedikit retakan retakan (crack) dan gumpalan (cluster) pada [4 permukaannya dibandingkan dengan hasil foto SEM permukaan baja tanpa penambahan inhibitor. Terlihat juga pada Gambar 9 menunjukkan hasil dengan konsentrasi inhibitor ekstrak daun teh sebesar 9\% dalam larutan korosif $\mathrm{HCl}$ dengan perbesaran 2000 kali terlihat berkurangnya gumpalan (cluster) dan berkurangnya juga retakan (crack) pada permukaan Baja API 5L yang menyebabkan terjadinya korosi. Hal ini menunjukkan bahwa seiring dengan penambahan konsentrasi inhibitor ekstrak daun teh, maka akan mengurangi kerusakan permukaan yang akan mengakibatkan terjadinya korosi pada Baja API $5 \mathrm{~L}$.

\section{KESIMPULAN}

Pengaruh konsentrasi inhibitor ekstrak daun teh terhadap laju korosi baja API 5L adalah semakin tinggi konsentrasi inhibitor ekstrak daun teh maka laju korosi baja API 5L semakin rendah. Efisiensi inhibisi ekstrak daun teh pun semakin meningkat seiring dengan meningkatnya konsentrasi inhibitor yang ditambahkan. Hasil antara baja API 5L yang menggunakan inhibitor ekstrak daun teh dengan yang tidak menggunakan inhibitor jelas berbeda, terbukti bahwasannya baja API 5L yang tidak menggunakan inhibitor menghasilkan nilai laju korosi yang lebih besar dari pada baja API 5L yang menggunakan inhibitor. Hasil tersebut menyatakan bahwa baja API 5L yang tidak menggunakan inhibitor akan cepat terkorosif. Persentase efisiensi inhibisi terbaik pada pelarut $\mathrm{NaCl}$ terdapat pada konsentrasi inhibitor $9 \%$ yaitu sebesar $95 \%$ dan pada pelarut korosif $\mathrm{HCl}$ terdapat pada konsentrasi $9 \%$ yaitu sebesar $45 \%$ pada waktu paparan selama 240 jam (10 hari).

\section{DAFTAR PUSTAKA}

[1] GAPSARI, Femiana. Pengantar Korosi. Universitas Brawijaya Press, 2017.

[2] LUDIANA, Yona; HANDANI, Sri. Pengaruh konsentrasi inhibitor ekstrak daun teh (Camelia Sinensis) terhadap laju korosi baja karbon schedule 40 Grade B ERW. Jurnal Fisika Unand, 2012.

[3] HERMAWAN, Beni. Ekstrak Bahan Alami sebagai Inhibitor korosi. Retrieved November 11: 2011.

[4] NUGROHO, Fajar. Penggunaan inhibitor untuk meningkatkan ketahanan korosi pada baja karbon rendah. Jurnal Angkasa, 2015.

[5] Tim Penelitian dan Pengembangan Industri, 2013, Kandungan Senyawa Kimia pada Daun Teh (Camelia Sinensis), Warta penelitian dan pengembangan industri, Vol. 19. P. 12-16.

[6] SARI, Desi Mitra; HANDANI, Sri; YETRI, Yuli. Pengendalian laju korosi baja ST-37 dalam medium asam klorida dan natrium klorida menggunakan inhibitor ekstrak daun teh (Camelia Sinensis). Jurnal Fisika Unand, 2013.

[7] PATTIREUW, Kevin Jones; RAUF, Fentje Abdul; LUMINTANG, Romels Cresano Apelles. Analisis laju korosi pada baja karbon dengan Menggunakan air laut dan H2SO4. JURNAL ONLINE POROS TEKNIK MESIN UNSRAT, 2013, 2.1.

[8] PRIYOTOMO, Gadang. Korosi Retak Tegang Material Stainless Steel AISI 304 Di Lingkungan $\mathrm{MgCl} 2.2008$. 
[9] BAYUSENO, Athanasius Priharyoto. Analisa Laju Korosi Pada Baja Untuk Material Kapal Dengan Dan Tanpa Perlindungan Cat. Rotasi, 2009, 11.3: 32-37.

[10] ROCHMAT, Agus; LIANTONY, Galih; SEPTIANANDA, Yuki Diens. UJI KEMAMPUAN TANIN DAUN KETAPANG SEBAGAI INHIBISI KOROSI PADA BAJA MILD STEEL DALAM PIPELINE. JURNAL INTEGRASI PROSES, 2019, 8.1: 45-50. 